Pecvnia, núm. 12 (enero-junio, 2011), pp. 71-89

\title{
LA EMPRESA FAMILIAR Y LA SOCIEDAD LEGAL DE GANANCIALES Y SU SULESIÍN
}

Carlos Miguélez del Río ${ }^{1}$ cmigr@unileon.es Universidad de León

fecha de recepción: 01/03/2011

fecha de aceptación: 15/04/2011

\section{Resumen}

Este trabajo hace referencia a la problemática derivada de la existencia de la empresa familiar y a las características específicas de las explotaciones familiares, especialmente las de asegurar la conservación y continuación de la misma. Ante la falta de una regulación específica en la materia, estudiaremos la normativa común sobre la empresa familiar dentro del régimen económico del matrimonio y la sucesión de la misma. Con esta finalidad examinaremos las nuevas reformas introducidas en nuestro ordenamiento jurídico contemplando la empresa familiar, tanto como bien ganancial, como privativo, como integrada por bienes privativos y gananciales, así como en cuanto a sus beneficios y pérdidas y los efectos que en ella produce la liquidación de la sociedad ganancial. Efectuaremos también un estudio específico del protocolo familiar y de las formas de sucesión de la empresa familiar, con mención concreta al novedoso contenido del art. 1056 del Cc y a las facultades de mejora de hijos o descendientes, para concluir con las notas más importantes de los pactos sucesorios y su trascendencia jurídica.

Palabras clave: Empresa familiar; Sociedad de gananciales; Liquidación de la sociedad de gananciales; Bienes privativos; Bienes gananciales; Protocolo familiar, herederos forzosos; Legítima; Mejora; Pactos sucesorios.

\section{Abstract}

His work refers to the problematics derived from the existence of the family business and to the specific characteristics of the familiar developments, specially them of assuring the

1 Magistrado y Profesor Asociado. Derecho Mercantil, Facultad de Derecho, Campus de Vegazana, s/n, 24071-León (España). 
conservation and continuation of the same one. Before the lack of a specific regulation in the matter, we will study the common regulation on the family business inside the economic regime of the marriage and the succession of the same one. With this purpose we will examine the new reforms got in our juridical classification contemplating the family business, so much as profit good, since exclusively, since integrated by exclusive and profit goods, as well as for his benefits and losses and the effects that in her there produces the liquidation of the profit company. We will effect also a specific study of the familiar protocol and of the forms of succession of the family enterprise, with mention it makes concrete to the new content of the art. 1056 of the $\mathrm{Cc}$ and to the powers of improvement of children or descendants, to conclude with the most important notes of the successor agreements and his juridical transcendency.

Keywords: Family business; System of shared assets; Liquidation of the system of shared assets; Private assets; Shared assets; Family protocol, Necessary inheritors; Legitimate; Improvement; Inheritance agreements.

\section{La empresa familiar y la sociedad legal de gananciales}

\section{1. ¿Qué es la empresa familiar?}

De sobra es conocido por todos que, independientemente del tamaño o de la clase de actividad de que se trate, existen empresas en las que el capital o la gestión o el gobierno de las mismas, está en manos de una o de varias familias. Estas entidades pueden ser empresas pequeñas, medianas o grandes y, su forma de organización, puede ser la de una empresa individual o colectiva o sociedad. Pues bien, hoy día se admite por todos que la empresa familiar está vinculada a un principio elemental y comprensible cual es la idea de supervivencia de la empresa, pudiendo señalarse dos notas que la caracterizan: a) se trata de empresas unifamiliares o multifamiliares en las que la capacidad de control político lo ejercen uno o varios miembros de la familia; y b) es deseo y voluntad de los propietarios de la empresa la idea de permanencia, es decir, que continúe en manos y en poder de la propia familia. Es precisamente por esta razón por la que suele establecerse el llamado protocolo familiar para que la empresa se mantenga dentro de la familia mediante la incorporación de sucesivas generaciones familiares, como diremos con posterioridad.

No existe en nuestro ordenamiento jurídico un concepto legal de empresa familiar, sin embargo la realidad económica demuestra su existencia y su importancia en todos la países, no solo en España, por ejemplo en Francia el 60,5\% de las empresas son de origen familiar, en Italia e $75 \%$, en Alemania el $82 \%$, en el Reino Unido el $76 \%$, en Estados Unidos el $90 \%$ y, en España el 71\% de la empresas que, en el año 1998, facturaban más de 200 millones de pesetas al año eran empresas familiares, según el número 12-1998 de la Colección de Estudios e Informes editado por la Caixa, Gallo (1998). En la Asamblea General GEEF, celebrada el día 27 de marzo de 2008, se definió 
la empresa familiar como aquella en la que, tenga el tamaño que tenga, la mayoría de los votos son propiedad de la persona o personas de la familia que fundó o fundaron la compañía, o son propiedad de la persona que tiene o ha adquirido el capital social de la empresa, o son propiedad de sus esposas, padres, hijos o herederos directos del hijo, pudiendo ser la mayoría de los votos directa o indirecta, cuando al menos un representante de la familia o pariente participa en la gestión o gobierno de la compañía. Y a las entidades cotizadas en bolsa, se les aplica la definición de empresa familiar si la persona que fundó o adquirió el capital social, o sus familiares o descendientes poseen el $25 \%$ de los derechos de voto a los que da derecho el capital social. Por su parte, la Comisión de Hacienda del Senado español, en noviembre de 2001, no definió lo que era la empresa familiar pero dictaminó las siguientes características: a) cuando una o varias familias tengan una participación importante del capital social; b) cuando la familia ejerza el control de la empresa; c) cuando algún miembro de la familia participe en la gestión de la sociedad; y d) cuando exista una vocación de continuidad y permanencia en seguir con su propiedad y gestión, incorporando a las futuras generaciones familiares. (BOCE, Senado, 23 de noviembre de 2001).

\subsection{De la sociedad legal de gananciales}

Conviene comenzar este breve estudio sobre la importancia y repercusión que la sociedad legal de gananciales tiene en la empresa familiar, partiendo de la base del concepto que, de la sociedad de gananciales, hace el art. 1344 del Cc, según el cual, "mediante la sociedad de gananciales se hacen comunes para los cónyuges las ganancias o beneficios obtenidos indistintamente por cualquiera de ellos, que les serán atribuidos por mitad al disolverse aquella". Ahora bien, no toda ganancia obtenida durante el matrimonio pude considerarse como ganancial, del mismo modo que pueden existir bienes privativos de los cónyuges a pesar de existir una sociedad ganancial, ni la existencia de bienes gananciales implica, siempre y necesariamente, la existencia de ganancias para los esposos.

Nos estamos pues refiriendo a un régimen económico matrimonial que, según se dice en el art. 1316 del Cc, rige como sistema legal supletorio para los ciudadanos españoles sometidos al derecho común, conforme se deduce del art. 1315 de la misma norma jurídica.

Si bien la sociedad de gananciales comparte importantes aspectos con las sociedades civiles, parece claro que la sociedad de gananciales no participa de la misma naturaleza jurídica que las sociedades a las que se refieren los arts. 35 y 36 del Cc, en cuanto que la sociedad de gananciales se caracteriza por la creación de un patrimonio separado y colectivo, es decir, de un patrimonio común que, conjuntamente, ha de distribuirse entre el marido y la mujer.

Toda empresa familiar puede ser estudiada desde tres puntos de vista, conforme tiene indicado la Profesora Reyes López (2005), como bien privativo, como bien ganancial y como bien privativo y ganancial. 


\subsection{La empresa como bien privativo}

Tiene ello lugar cuando la empresa ha iniciado su ejercicio por alguno de los cónyuges con anterioridad a la celebración del matrimonio. Es el art. 1346 del Cc el que indica cuales son los bienes privativos de cada uno de los cónyuges.

Examinando dicho precepto jurídico comprobamos que no se define lo que se debe entender por bienes privativos y que solamente se establece una larga enumeración que, consideramos debe ser de carácter taxativo: el legislador español parte, en primer lugar, del momento de la adquisición de los bienes para determinar cuando son privativos de uno de los cónyuges, independientemente de que se hubiesen adquirido de forma onerosa o gratuita.

A este propósito, el legislador sienta la regla general de que serán bienes privativos los que, al comenzar la sociedad de gananciales, pertenezcan a cada uno de los cónyuges; los adquiridos por cada uno de los cónyuges por título gratuito después de comenzar la sociedad; los adquiridos por título oneroso cuando el bien objeto de la contraprestación fuese privativo; los bienes adquiridos por derecho de retracto perteneciente a uno de los esposos, entendiéndose que el supuesto abarca tanto el retracto legal, como el convencional, como el arrendaticio; los bienes y derechos patrimoniales inherentes a la persona que, como es notorio y conocido, nada tienen que ver con los derechos de la personalidad o con los bienes de la persona, por cuanto estos bienes no se patrimoniales, nos estamos refiriendo a los derechos derivados de la propia imagen, intelectuales, etc.; los bienes y derechos patrimoniales no transmisibles inter vivos, se está refiriendo aquí el legislador a aquellos bienes o derechos subjetivos adquiridos durante vigencia de la sociedad de gananciales en virtud de contratos o actos realizados por circunstancias personalísimas de uno de los cónyuges, como por ejemplo los derechos de un socio industrial; el resarcimiento por daños sufridos a la persona de uno de los cónyuges o a sus bienes privativos, como tendrá lugar cuando uno de los esposos sufra daños por atentado contra su integridad física o psíquica o contra el honor, etc.; las ropas objeto de uso personal que no tengan un valor extraordinario o los instrumentos necesarios para el ejercicio de la profesión u oficio de uno de los cónyuges; y, en último lugar, la adquisición de bienes privativos con fondos comunes concede al patrimonio ganancial un crédito por el valor satisfecho contra el cónyuge titular de esos bienes privativos, tal como dispone el art. 1358 del Cc.

\subsection{La empresa como bien ganancial}

Tiene lugar cuando la empresa sea constituida durante la vigencia del matrimonio y con fondos gananciales. En este sentido, dentro de la empresa habrán de incluirse no sólo los bienes y derechos comunes de ambos cónyuges que formen parte del activo de la comunidad, sino también los beneficios generados por los mismos.

Tengamos en cuenta que según los arts. 1344 y 1347 del Cc se hacen comunes las ganancias o beneficios obtenidos por cualquiera de los cónyuges, los obtenidos por la industria o por el trabajo de cada uno de los esposos, los frutos, rentas o intereses que produzcan tanto los bienes privativos como los gananciales, los adquiridos a título 
oneroso a costa del caudal común o por derecho de retracto de carácter ganancial y las empresas y establecimientos fundados durante la vigencia de la sociedad por cualquiera de los cónyuges a expensas de los bienes comunes.

Efectivamente, las empresas o establecimientos de explotación lucrativa son auténticas adquisiciones a título ganancial, siempre y cuando se cumplan dos requisitos legales, el primero que se adquiera a título oneroso y, el segundo, que se efectúe a costa del caudal común.

\subsection{Empresa integrada por bienes privativos y gananciales}

Se da este supuesto bien cuando la empresa se constituye durante la vigencia del régimen ganancial pero con capital privado de los cónyuges y con bienes o derechos gananciales, o bien cuando la empresa se ha constituido antes de la celebración del matrimonio con capital privado de uno de los esposos y con la aportación posterior de bienes o derechos gananciales.

En este sentido, son dos las referencias legales existentes para la determinación de la naturaleza jurídica de la empresa familiar constituida en parte con bienes privativos de uno de los cónyuges y en parte con bienes gananciales, concretamente los arts. 1354 y 1355 del Cc.

Desde luego, si los cónyuges adquiriesen un bien en parte con dinero privativo de uno de los cónyuges y si en el contrato correspondiente, se hiciese mención a las correspondientes cuotas pertenecientes a la comunidad de gananciales y al cónyuge que satisfizo parte del precio con dinero privativo, el art. 1354 del Cc establece que los bienes adquiridos mediante precio en parte ganancial y en parte privativo, corresponderá proindiviso a la sociedad de gananciales y al cónyuge en proporción al valor de las aportaciones. En definitiva, si ocurriese tal supuesto estaríamos en presencia en un bien perteneciente a una sociedad especial, al carecer de personalidad jurídica la sociedad de gananciales.

Por el contrario, el art. 1355 del Cc establece que los cónyuges, de mutuo acuerdo, podrán atribuir la condición de gananciales a los bienes que adquieran a título oneroso durante el matrimonio y ello con independencia de cuál sea la procedencia del precio y la forma de plazos en que se satisfaga, añadiendo dicho precepto que, si la adquisición se hace forma conjunta y sin atribución de cuotas, se presumirá su voluntad favorable al carácter ganancial de tales bienes. Es decir, nos encontramos ante la posibilidad de que los cónyuges puedan decidir sobre la condición de un bien ganancial adquirido onerosamente durante el matrimonio, y ello al margen de la procedencia del precio o, lo que es lo mismo, ello es reflejo del principio de que los cónyuges pueden celebrar entre sí todo tipo de contratos, como indica el art. 1323 del Cc. El resultado de ese pacto de los cónyuges es que el bien adquirido no será presuntamente ganancial, sino que será real y e indudablemente ganancial.

Pues bien, en el supuesto de que una empresa hubiese sido fundada con capital privativo y capital común, el art. 1347 del Cc indica que se aplicará lo dispuesto en el art. 1354 de 
la misma norma jurídica. Como sostiene el Profesor Peña Bernaldo de Quirós (1991), es difícil que una empresa se constituya durante la vigencia de la sociedad de gananciales por uno cualquiera de los cónyuges y que tenga carácter enteramente privativo, básicamente porque los arts. $1347.1^{\circ}$ y 1359 del Cc establecen que la aportación de trabajo de uno de los cónyuges debe ser considerada como capital común. Ahora bien, el hecho de que la empresa así constituida sea considerada, desde un punto de vista de calificación jurídica, como un bien ganancial no quiere decir que desaparezca en parte la titularidad sobre cada uno de los elementos que la integran, por lo tanto, el cónyuge que hubiese contribuido con sus bienes privativos a la fundación de la empresa familiar seguirá siendo titular proindiviso de la empresa en proporción a su participación privativa, al pertenecer la empresa proindiviso a la sociedad de gananciales y al cónyuge. En consecuencia, en el supuesto de disolución y liquidación de la sociedad legal de gananciales, no entrará en juego el contenido del art. 1358 del Cc, según el cual, cuando los bienes sean privativos o gananciales, con independencia de la procedencia del caudal con que la adquisición se realice, habrá de reembolsarse el valor satisfecho a costa, respectivamente, del caudal común o del propio, mediante el reintegro de su importe actualizado al tiempo de la liquidación, sino que el cónyuge que hubiese participado con sus bienes privativos en la fundación de la empresa tendrá derecho a una participación proporcional al valor de sus aportaciones.

\subsection{Disolución y liquidación de la sociedad de gananciales y sus efectos para la empresa familiar}

Es evidente que no puede haber matrimonio sin la existencia de régimen económico matrimonial $y$, de igual forma, tampoco es asumible que pueda existir un régimen matrimonial sin matrimonio. Conforme indica el art. 1392 del Cc, la sociedad de gananciales concluirá de pleno derecho cuando se disuelva el matrimonio, cuando sea declarado nulo, cuando judicialmente se decrete la separación de los cónyuges y, en último lugar, cuando los cónyuges convengan un régimen económico distinto.

Ahora bien, una vez iniciada la disolución y hasta el momento en que se aprueben las operaciones particionales conforme indican los arts. 1396 y siguientes del Cc, la comunidad de gananciales se convierte en una comunidad en liquidación $y$, en consecuencia, los bienes y derechos que adquieran cada uno de los cónyuges lo adquieren para su exclusivo patrimonio y no para el de la comunidad, cesando también el régimen de administración de bienes que hubiere estado vigente y no pueden contraerse obligaciones nuevas a cargo de la masa, restando solo el pago de las deudas existentes y, con posterioridad, cobrar los créditos pendientes y el reparto de los bienes y derechos. En palabras del Profesor Vázquez Iruzubieta (1997), nace así un régimen de indivisión que ya no es forzoso y, aunque el conjunto de bienes continúa perteneciendo a los cónyuges o a sus herederos, ya no puede ser definido como el patrimonio de una sociedad conyugal al haber desaparecido la finalidad de su existencia y encontrarse extinguidas las fuentes que la nutrían.

El legislador, para que la partición y adjudicación sean justas, equitativas, prácticas y útiles para los cónyuges, ha establecido un catálogo de normas que habrán de ser 
tenidas en cuenta siempre y cuando los bienes, derechos y beneficios de la comunidad así lo permitan.

El art. 1406 del Cc, en lo que aquí interesa, establecía que la explotación agrícola, comercial o industrial se incluirían con preferencia en el haber del cónyuge que los hubiera llevado con su trabajo. La reforma de dicha norma, efectuada por la Ley $7 / 2003$, ha variado la redacción de dicho precepto jurídico diciéndose en la actualidad que cada cónyuge tendrá derecho a que se incluya con preferencia en su haber, hasta donde éste alcance "la explotación económica que gestione efectivamente". Esta norma, sobre la Sociedad Limitada Nueva Empresa, ha introducido transformaciones en la legislación civil vigente en aquellos preceptos en los que se ordenan las relaciones entre los miembros de una familia y la sucesión de la unidad productiva para dotarla de instrumentos que permitan diseñar, en vida del emprendedor, la sucesión más adecuada de la empresa en todas sus posibles configuraciones: societarias, empresa individual, etc.

En el supuesto objeto de estudio, el referido precepto busca claramente proteger la empresa familiar con dos finalidades evidentes, por un lado la conservación de la empresa como unidad económica y, por otro, facilitar que el cónyuge empresario pueda continuar con la explotación económica que ha gestionado durante la vigencia de la sociedad de gananciales. Para que pueda darse tal preferencia como derecho potestativo del cónyuge, conceptuado como una opción legal, es preciso, como sostiene el Profesor García Urbano (1991), que se den los siguientes requisitos: a) que la empresa tenga la naturaleza jurídica de ganancial, incluso las empresas y establecimientos a los que se refiere el art. 1347.5 del Cc, es decir, los fundados durante la vigencia de la sociedad por uno de los cónyuges, pero a expensas de bienes comunes; y b) que constituya una explotación en sentido amplio, por lo tanto se incluirán cualquier tipo de empresas y explotaciones, siempre que el cónyuge hubiese gestionado, efectiva y realmente, la explotación con anterioridad a la liquidación de la sociedad.

\subsection{Beneficios generados por la empresa familiar}

Si partimos del principio comúnmente admitido, según el cual la empresa que no tiene beneficios y no crece está llamada a su desaparición, tenemos que convenir que la obtención de beneficios es un requisito imprescindible en toda empresa, fundamentalmente en la familiar donde, como ya sabemos, tiene como una de su finalidades básicas la supervivencia y la incorporación de futuras generaciones, y ello tanto a la propiedad como a la gestión.

En aplicación del art. 1347 del Cc, podemos decir que son bienes gananciales los obtenidos o producidos directamente por cualquiera de los cónyuges salvo, evidentemente, que se trate de derechos patrimoniales inherentes a la persona, la ropa y objetos de uso personal que no sean de extraordinario valor y los instrumentos necesarios para el ejercicio de la profesión, excepto cuando sean parte de un establecimiento o explotación de carácter común. Asimismo, será ganancial el beneficio derivado de la actividad de cualquiera de los cónyuges, las ganancias o beneficios obtenidos por éstos y los derivado de los bienes, sean privativos o gananciales, independientemente de que se obtengan o no con periodicidad. En el caso de subrogación de bienes gananciales, se 
convierten también en gananciales, aunque sólo se hubiesen adquirido por uno de los cónyuges; y, en último lugar, son gananciales los bienes adquiridos por derecho de retracto de carácter ganancial, y ello aunque se utilizase bienes fondos privativos de uno de los cónyuges, en cuyo caso el cónyuge titular de esos bienes será acreedor frente a la sociedad de gananciales y ésta será deudora del cónyuge en la forma que indica los arts. 1358 y 1364 del Cc.

En relación con las empresas y establecimientos, el párrafo $5^{\circ}$ del art. 1347 del Cc señala que los fundados durante la vigencia de la sociedad por uno de los cónyuges a expensas de los bienes comunes serán gananciales y, si concurre capital privado y capital común, pertenecerán proindiviso a la sociedad y al cónyuge en proporción al valor de sus respectivas aportaciones.

Por lo tanto, la empresa será ganancial cuando se haya fundado conjuntamente por ambos cónyuges y sus beneficios serán también gananciales, incluso en el supuesto de que se haya creado por uno solo de los cónyuges pero con bienes gananciales, por cuanto si lo obtenido por el ejercicio de la profesión de cualquiera de los cónyuges y por rendimientos de bienes privativos forma parte de la sociedad de gananciales, es lógico y justo que para el ejercicio de una profesión el patrimonio ganancial facilite a los cónyuges los bienes y medios necesarios para ello.

\subsection{Deudas de la empresa familiar}

Según dispone el art. 1367 del Cc, los bienes gananciales responderán de las obligaciones contraídas por los dos cónyuges conjuntamente o por uno de ellos con el consentimiento del otro. Así las cosas, salvo casos muy especiales, si los cónyuges no actúan conjuntamente o uno solo de ellos con el consentimiento del otro, no es lícito contraer obligaciones con cargo a la empresa familiar.

Por lo tanto, como norma general, los actos contraídos por uno solo de los cónyuges que supongan obligaciones para la sociedad de gananciales carecerán de valor jurídico alguno, pero no olvidemos que según el art. 1322 del Cc cuando se requiera para un acto de administración o disposición que uno de los cónyuges actúe con el consentimiento del otro, los realizados sin él y cuando no hayan sido confirmados, podrán ser anulados a instancia del cónyuge cuyo consentimiento se haya omitido, sin perjuicio de que serán nulos los actos realizados a título gratuito sobre bienes comunes si falta el consentimiento del otro cónyuge.

Ahora bien ¿es posible que dentro de una empresa familiar, ambos cónyuges puedan establecer pactos o convenciones que prevalezcan sobre las referidas limitaciones legales? La doctrina mayoritariamente entiende que sí, por ejemplo la Profesora Herrero García, admitiéndose en este sentido que las estipulaciones capitulares puedan asimilarse a las normas legales, de tal forma que mediante consentimiento válido pactado voluntariamente por los dos cónyuges sería lícito pactar la supresión de dicho consentimiento para la administración y disposición de bienes gananciales, siempre y cuando tal dispensa tenga valor en términos de reciprocidad entre los cónyuges, tal como se deriva del art. 1328 del Cc donde se dice que serán nulas cualquier estipulación 
contraria a las leyes o a las buenas costumbres o limitativa de la igualdad de derechos que corresponde a cada cónyuge.

\subsection{El protocolo familiar}

Sí, como antes hemos indicado, uno de los problemas más importantes que tiene la empresa familiar surge en orden a determinar sobre su continuidad y mantenimiento, el protocolo familiar puede contribuir a conseguir tales objetivos mediante una serie de acuerdos que pueden adoptarse por los interesados. De esta forma puede definirse como un conjunto de reglas dadas entre los miembros de la familia que, fundamentalmente, están encaminadas a regular tanto la organización y gestión de la empresa, como las relaciones profesionales entre sus miembros entre las cuales, lógicamente, pueden también incluirse los relativos a la sucesión de la empresa y a la elección y designación del sucesor o sucesores.

La Guía para la Pequeña y Mediana Empresa Familiar redactada en el año 2003 por la Dirección General de las PYME, haciéndose eco de las recomendaciones del Informe de la Comisión Especial del Senado del año 2001 sobre la problemática de la empresa familiar, recoge la necesidad de que las empresas familiares formalicen un protocolo como acuerdo que delimite el marco de desarrollo, las reglas de actuación y las relaciones entre la empresa familiar y su propiedad. En este mismo sentido se indica también por la Ley $7 / 2003$ sobre la sociedad limitada nueva empresa.

Como todo pacto o contrato, es preciso que el protocolo familiar sea asumido por todos los miembros del grupo familiar y que cuente con su consentimiento, por cuanto sin ello no será posible el cumplimiento de una de sus finalidades básicas, cual es la prevención de conflictos que puedan nacer en el seno de la empresa familiar y su adaptación a las nuevas realidades empresariales y familiares.

Precisamente por ello se suelen establecer mecanismos para ir adaptando el protocolo a los nuevos tiempos de la empresa, gozando así de la característica de la autorregulación en cuanto que no se impone a ninguna empresa familiar.

No existe limitación alguna sobre el contenido del protocolo familiar, por lo que debemos entender que siempre que no sean contrarios a la ley o al orden público o perjudiquen a terceras personas, pueden tratar sobre cualquier cuestión que afecte a la empresa familiar y puede incluirse en los estatutos de la sociedad o, por el contrario, no incorporarse a ellos. No obstante, sí se considera conveniente su determinación para configurar las relaciones entre la familia y la empresa en temas como la preparación del sucesor o la preparación y organización para la sucesión o las relaciones entre el predecesor y la familia o el establecimiento de un derecho de usufructo sobre la empresa de algún familiar mientras que el fundador sigue ostentando el derecho de propiedad, etc. No existe pues ningún prototipo de contenido del protocolo, pudiendo haber tantos y distintos como tantas empresas familiares.

Ahora bien, tampoco debemos olvidar que el protocolo familiar, además de un pacto o contrato entre los integrantes de círculo familiar, constituye también un marco de pautas 
de conducta que los miembros se comprometen a cumplir y que, al margen de las penalizaciones que puedan establecerse por sus incumplimientos, adquieren el compromiso de cumplir en interés de la familia y de la empresa familiar, intentando anticiparse a los posibles problemas y a las diferentes situaciones que puedan afectar a la empresa en el futuro para buscar resolver la situación cuando realmente se presenten.

En consecuencia, en todo protocolo familiar es preciso distinguir entre las reglas que tienen para las partes valor contractual y cuyo cumplimiento podrá ser impuesto y aquellas otras que tienen un mero contenido moral o referencial y sin ningún valor coercitivo.

En último lugar indicar, como pone de manifiesto la Profesora Parra Lucán (2008), que muchas veces la aplicación de normas que permiten adjudicar la empresa familiar a un solo sucesor son claramente insuficientes para resolver todos los problemas y conflictos que puedan darse, particularmente en relación a la titularidad de la explotación; a la profesionalización de los gestores; al favorecimiento de aquellos hijos que con su trabajo y dedicación han permanecido en la empresa, o a la forma de hacer efectiva la retribución de los familiares encargados de la gestión de la empresa con la participación en la propiedad de todos los herederos. Todas estas circunstancias y otras similares son las que han hecho posible que el protocolo familiar se haya desarrollado también en el ámbito de la sucesión de las empresas familiares, teniendo el significado de una especie de contrato o de pacto entre los miembros de una familia para que, por supuesto respetando la legítima de los herederos forzosos, asuman el compromiso de cumplimiento de una serie de reglas sobre el funcionamiento de la empresa familiar.

\section{La sucesión en la empresa familiar}

\subsection{Cuestiones generales}

Ya sabemos que una de las características más importantes de la empresa familiar es la vocación de continuidad y permanencia, en la vocación de seguir con su propiedad y gestión, incorporando a sucesivas generaciones. Pues bien, en relación con este tema, es claro que la sucesión de la empresa puede convertirse en uno de los puntos conflictivos que puede darse en toda empresa familiar. Así es, es un hecho notorio que pueden surgir problemas por diferentes acontecimientos que pueden darse en el proceso sucesorio, ya sea porque el familiar fundador de la empresa ponga reparos a la sucesión o en cuanto al nombramiento y elección del sucesor, pudiendo suscitarse discrepancias entre el fundador y al candidato elegido sobre la forma de seguir con la gestión y dirección de la empresa familiar.

Históricamente no ha sido infrecuente que el fundador no siempre daba cumplimiento a las normas legales que regulaban toda sucesión hereditaria, concretamente nos estamos refiriendo a los requisitos que establecen los arts. 806 y siguientes del Cc. En esta regulación, después de afirmar que la legítima es la porción de bienes de que el testador no puede disponer por haberla reservado la ley a determinados herederos, llamados herederos forzosos, señala que son herederos forzosos los hijos y descendientes respecto 
de sus padres y ascendientes; a falta de los anteriores, los padres y ascendientes respecto de sus hijos y descendientes y el viudo o la viuda en los términos indicados en la ley. Y asimismo establece que constituyen la legítima de los hijos y descendientes las dos terceras partes del haber hereditario del padre o de la madre, sin perjuicio de que éstos puedan disponer de una parte de las dos que forman la legítima, para aplicarla como mejora a sus hijos o descendientes.

En este sentido, para tratar de evitar los problemas derivados de las limitaciones que imponen las normas sucesorias, el legislador en el año 2003 modificó el párrafo segundo del art. 1056 del Cc como luego expondremos.

El fundador de la empresa familiar puede proceder a la disposición de la empresa incorporando gradualmente a sus sucesores con anterioridad a su fallecimiento, o transmitiendo la totalidad de la empresa de una sola vez en vida o, bien, posponiendo la sucesión hasta el momento de su muerte. Nosotros vamos a referirnos aquí a este último supuesto, y teniendo en cuenta que en nuestro Ordenamiento Jurídico existen normas que regulan la sucesión (legislación común y foral), dependiendo de cuál sea la vecindad civil del fundador y causante de la herencia; ante esta duplicidad normas sucesorias este trabajo estará basado en la legislación prevista en nuestro Código Civil. Vamos pues a tratar un tema de suma importancia para la supervivencia de la empresa familiar por cuanto las estadísticas ponen de manifiesto que el $70 \%$ de los negocios familiares desaparecen después de la muerte del fundador y que sólo entre un 9 y un 15\% consiguen llegar a la tercera generación, según el Instituto de la Empresa Familiar.

Sin duda, la forma más importante de sucesión de los bienes que forman parte de la herencia se realiza mediante el otorgamiento de un testamento. El art. 667 del Cc define el testamento como el acto por el cual una persona dispone para después de su muerte de todos sus bienes o de parte de ellos. No obstante, debemos también señalar que dicha definición es ciertamente incompleta por cuanto la norma permite el otorgamiento de testamento con un contenido que nada tiene que ver con la disposición de bienes por parte del testador. Así, por ejemplo, mediante testamento se puede reconocer a un hijo como indica el art. 124 del Cc o designar beneficiario en el contrato de seguro de personas en los términos que indica el art. 84 de la LCS, y todo ello al margen del contenido del art. 747 del Cc, donde se establecen unas normas determinativas e interpretativas para facilitar el cumplimiento de la voluntad del testador.

Son características del testamento las siguientes: la unilateralidad, por cuanto su otorgamiento depende de la voluntad de una sola persona; la exclusividad, puesto que se trata de un acto personalísimo y la decisión y el contenido no puede encargarse a un mandatario o representante; la irreceptibilidad, ya que no se precisa para su otorgamiento que sea conocido por terceras personas; la solemnidad, porque para su validez se requiere el cumplimiento de ciertas formalidades legales que, si no se cumplen, hace que el testamento sea nulo; y la revocabilidad, en el sentido de que puede ser cambiado por el testador cuantas veces lo desee.

Desde luego, si se cumplen los requisitos legales exigidos, especialmente en cuanto a los derechos legítimos de los herederos, mediante el testamento se puede transmitir una 
empresa familiar a través de diversos mecanismos. Así, por ejemplo: estableciendo un usufructo universal de la herencia a favor del cónyuge supérstite (arts. 834 y siguientes del (c); disponiendo el testador que al realizarse la partición se adjudique la empresa familiar a uno o varios herederos determinados, como dispone el art. 1056 del Cc; mejorando a favor de alguno o algunos de sus hijos o descendientes de tal forma que se garantice así la continuidad de la empresa familiar (art. 831 del Cc); mediante las sustituciones fideicomisarias, en virtud de las cuales se encarga al heredero que conserve o trasmita a un tercero la empresa familiar, tal como se deriva del art. 781 del Cc; o, en último lugar, instituyendo un legado y acordando la transmisión de la empresa familia de acuerdo con los arts. 858 y siguientes de la misma norma jurídica.

\subsection{Situación actual en nuestro Código Civil (art. 1056)}

Dentro de las posibilidades que ofrece la norma para la sucesión de la empresa familiar destaca, por su importancia y relativa novedad, el supuesto previsto en el art. 1056 del Cc, reformado por la Ley 7/2003. El legislador ha dado un paso al frente en favor de la libertad de testar sobre la transmisión de una empresa familiar, tratando de solucionar las dificultades derivadas de las legítimas de los herederos forzosos y la necesidad de respetarlas.

El precepto establece que "cuando el testador hiciere, por acto entre vivos o por última voluntad, la partición de sus bienes, se pasará por ella, en cuanto no perjudique a la legítima de los herederos. El testador que en atención a la conservación de la empresa o en interés de su familia quiera preservar indivisa una explotación económica o bien mantener el control de una sociedad de capital grupo de éstas podrá usar de la facultad concedida en este artículo, disponiendo que se pague en metálico su legítima a los demás interesados. A tal efecto, no será necesario que exista metálico suficiente en la herencia para el pago, siendo posible realizar el abono con efectivo extrahereditario y establecer por el testador o por el contador-partidor por él designado aplazamiento, siempre que éste no supere cinco años a contar desde el fallecimiento del testador; podrá ser también de aplicación cualquier otro medio de extinción de las obligaciones. Si no se hubiere establecido la forma de pago, cualquier legitimario podrá exigir su legítima en bienes de la herencia. No será de aplicación a la partición así realizada lo dispuesto en el artículo 843 y en el párrafo primero del artículo 844".

Además, debemos también recordar que la Ley 7/3003 modificó asimismo el párrafo segundo del art. 1271 del Cc, donde se dice que "sobre la herencia futura no se podrá, sin embargo, celebrar otros contratos que aquellos cuyo objeto sea practicar entre vivos la división de un caudal y otras disposiciones particionales, en orden a la sucesión en la empresa familiar, conforme al artículo 1056 párrafo segundo".

Por lo tanto, de acuerdo con lo indicado en dichos preceptos, el legislador permite al testador la posibilidad de atribuir la empresa familiar a aquel o aquellos miembros de la unidad familiar que considere más capacitados para regir la empresa, imponiendo a aquel heredero que no respete tal decisión la sanción de ver reducida su participación en la herencia a la legítima estricta. Es decir, el legislador autoriza al testador o al contador partidor expresamente autorizado para ello, adjudicar la empresa familiar a aquel 
heredero a quien considere más adecuado para defender en el futuro los intereses de la explotación.

La redacción del art. 1056 del Cc ha dado lugar a no pocas interpretaciones contradictorias en cuanto a si es posible que el fundador atribuya la empresa a un tercero ajeno a la familia, de igual manera que no impone que el testador tenga que ser siempre el padre y que el heredero adjudicatario sea siempre un hijo, al utilizar la norma los vocablos de testador y de interesados. Así las cosas, para un sector doctrinal es perfectamente posible que, si el testador lo considera conveniente, incluso la empresa familiar puede adjudicarla a una persona no perteneciente al ámbito familiar, por supuesto siempre que asuma la obligación de responder con dinero la satisfacción de la legítima a los herederos forzosos, por cuanto la legítima es sólo un derecho de crédito. En cambio, para otros autores es preciso que la transmisión del negocio familiar se haga a favor de un heredero, tal como señala la Profesora Parra Lucán (2008). Nosotros, interpretando la norma conforme a los principios que inspiran la empresa familiar, consideramos que ambas posturas no son totalmente ciertas $y$, por lo tanto, son parcialmente erróneas, siendo partidarios de una postura ecléctica. A nuestro juicio, aceptar sin ningún requisito la primera interpretación significaría la perdida de una de las características más importantes de la explotación familiar, cual es la de la incorporación de nuevas generaciones futuras, razón por la que siendo, a nuestro entender, posible que el testador designe a un sucesor en la empresa familiar ajeno a su círculo de familiares, siempre será necesario que la familia tenga una importante participación o ejerza un control sobre la misma o, al menos, algún miembro de la familia participe en la gestión de la empresa, para que así sean compatibles el interés de la familia y también la conservación de la misma.

Otra de las novedades más importantes de la reforma comentada se refiere al pago de la legítima en metálico a los herederos forzosos. Se desprende del art. 1056 del Cc que no es necesario que en el caudal hereditario existan bienes suficientes para el pago en metálico de la legítima, por cuanto se permite satisfacer su importe con dinero extrahereditario y que el testador o contador por él designado puedan aplazar el pago, siempre que no supere cinco años a contar desde el fallecimiento del testador. Es más, el legislador establece también la posibilidad de que el pago se realice por cualquier otro medio de extinción de las obligaciones, en la forma que indican los arts. 1157 del Cc. Sin embargo, si no se hubiese establecido la forma de pago, cualquier legitimario podrá exigir el pago de su legítima en bienes de la herencia, sin que ello requiera aprobación judicial (art. 843 del Cc), ni que sea preciso hacérselo saber a quienes resulten ser los futuros perceptores del pago en metálico de la legítima, en el plazo de un año de caducidad que establece el art. 844 de la misma norma jurídica.

Es preciso también hacer una referencia, siquiera sea breve, al contenido de los arts. 841 y 842 del Cc, donde se dice que el testador o el contador partidor autorizado podrá adjudicar todos los bienes hereditarios, o parte de ellos, a alguno de los hijos o descendientes, ordenando que se pague en metálico la porción hereditaria de los demás legitimarios y que, cualquiera de los hijos y descendientes obligados a pagar en metálico la cuota hereditaria de sus hermanos podrá exigir que se satisfaga en bienes de la herencia. Estos preceptos fueron reformados por la Ley 11/1981 y, desde entonces, el 
legislador permite al testador o al contador partidor autorizado a que cuando existan varios hijos o descendientes, prueba de ello es que en caso contrario no tendría ningún sentido el pago en metálico a los demás legitimarios, pueda adjudicar todos o parte de los bienes de la herencia a alguno de los hijos o descendientes. Y ello con independencia de que los bienes puedan o no ser divisibles y con el único límite de que se respete la porción hereditaria de los demás legitimarios, estando obligados los herederos adjudicatarios a cumplir con la voluntad del testador recibiendo los bienes que les han sido adjudicados puesto que, de lo contrario, se deben someter a las reglas comunes que el Código Civil establece para las particiones.

Un examen del contenido actual del art. 1056 del Cc y los preceptos antes indicados, introducidos por la Ley 11/1981, nos conduce a las siguientes conclusiones:

a) la facultad que el art. 841 del Cc concede al testador de adjudicar los bienes hereditarios no exige la existencia de una empresa, sociedad o explotación familiar, requisito que sí es necesario en el supuesto contemplado en el art. 1056 del Cc;

b) mientras que según dispone el art. 842 del Cc los hijos o descendientes obligados a pagar en metálico la cuota hereditaria pueden exigir el pago en bienes de la herencia, en el art. 1056 del Cc los adjudicatarios de la empresa pueden incluso satisfacer la legítima con bienes que no forman parte del caudal hereditaria, sin que los herederos legitimarios puedan oponerse a ello;

c) el pago de la legítima que impone el art. 841 del Cc es inmediato y, sin embargo, el art. 1056 permite el pago diferido al establecer la posibilidad de aplazamiento siempre que no supere el de cinco años desde el fallecimiento del testador;

d) así como el art. 841 del Cc no establece ningún requisito previo o finalidad en la decisión del testador para la adjudicación de los bienes, el art. 1056 del Cc impone que se realice en atención a la conservación de la empresa o en interés de la familia y para preservar indivisa la explotación económica; y

e) el art. 841 del Cc impone la obligación de que el adjudicatario sea hijo o descendiente del testador, cuando el art. 1056 del Cc permite que se adjudique la empresa familiar a cualquier interesado, en los términos anteriormente indicados.

\subsection{Facultades de mejora a hijos o descendientes}

Resulta interesante, a los efectos que nos ocupan, hacer una breve mención al supuesto previsto en el art. 831 del Cc, reformado por la Ley 41/2003, que contempla la posibilidad de adjudicar a favor de hijos o descendientes una empresa familiar a través de una especie de fiducia sucesoria. Dice así:

“1. No obstante lo dispuesto en el artículo anterior, podrán conferirse facultades al cónyuge en testamento para que, fallecido el testador, pueda realizar a favor de los hijos o descendientes comunes mejoras incluso con cargo al tercio de libre disposición y, en general, adjudicaciones o atribuciones de bienes concretos por cualquier título o concepto sucesorio o particiones, incluidas las que tengan por objeto bienes de la sociedad conyugal disuelta que esté sin liquidar. 
Estas mejoras, adjudicaciones o atribuciones podrán realizarse por el cónyuge en uno o varios actos, simultáneos o sucesivos. Si no se le hubiere conferido la facultad de hacerlo en su propio testamento o no se le hubiere señalado plazo, tendrá el de dos años contados desde la apertura de la sucesión o, en su caso, desde la emancipación del último de los hijos comunes.

Las disposiciones del cónyuge que tengan por objeto bienes específicos y determinados, además de conferir la propiedad al hijo o descendiente favorecido, le conferirán también la posesión por el hecho de su aceptación, salvo que en ellas se establezca otra cosa.

2. Corresponderá al cónyuge sobreviviente la administración de los bienes sobre los que pendan las facultades a que se refiere el párrafo anterior.

3. El cónyuge, al ejercitar las facultades encomendadas, deberá respetar las legítimas estrictas de los descendientes comunes y las mejoras y demás disposiciones del causante en favor de ésos.

De no respetarse la legítima estricta de algún descendiente común o la cuota de participación en los bienes relictos que en su favor hubiere ordenado el causante, el perjudicado podrá pedir que se rescindan los actos del cónyuge en cuanto sea necesario para dar satisfacción al interés lesionado.

Se entenderán respetadas las disposiciones del causante a favor de los hijos o descendientes comunes y las legítimas cuando unas $u$ otras resulten suficientemente satisfechas aunque en todo o en parte lo hayan sido con bienes pertenecientes solo al cónyuge que ejercite las facultades.

4. La concesión al cónyuge de las facultades expresadas no alterará el régimen de las legítimas ni el de las disposiciones del causante, cuando el favorecido por unas u otras no sea descendiente común. En tal caso, el cónyuge que no sea pariente en línea recta del favorecido tendrá poderes, en cuanto a los bienes afectos a esas facultades, para actuar por cuenta de los descendientes comunes en los actos de ejecución o de adjudicación relativos a tales legítimas o disposiciones.

Cuando algún descendiente que no lo sea del cónyuge supérstite hubiera sufrido preterición no intencional en la herencia del premuerto, el ejercicio de las facultades encomendadas al cónyuge no podrá menoscabar la parte del preterido.

5. Las facultades conferidas al cónyuge cesarán desde que hubiere pasado a ulterior matrimonio o a relación de hecho análoga o tenido algún hijo no común, salvo que el testador hubiera dispuesto otra cosa.

6. Las disposiciones de los párrafos anteriores también serán de aplicación cuando las personas con descendencia común no estén casadas entre sí’”.

Ley 41/2003, de 18 de noviembre, de protección patrimonial de las personas con discapacidad y de modificación del Código civil, pretendió proteger el patrimonio de las personas con discapacidad pero, al mismo tiempo, modificó algunos artículos del Cc relativos al derecho sucesorio sin que se vea en ellos beneficio alguno para los incapaces. Según se afirma en la Exposición de Motivos del Proyecto de la citada Ley de Protección del Patrimonio de las personas con discapacidad, se reforma el artículo 831 del CC al objeto de introducir una figura de protección patrimonial indirecta de las personas con discapacidad, concediéndose al testador la posibilidad de conferir al cónyuge sobreviviente la facultad de mejorar y distribuir la herencia del difunto entre los hijos y 
descendientes comunes, lo que permitirá no precipitar la partición de la herencia cuando uno de los hijos o descendientes tenga una discapacidad, y aplazar dicha distribución a un momento posterior, en el que podrán tenerse en cuenta la variación de las circunstancias y la situación actual de las personas con discapacidad. Tal facultad pueden concedérsela, además, los progenitores con descendencia común, aunque no estén casados entre sí. El precepto, por lo tanto, puede ser utilizado por cualquier matrimonio o pareja con descendencia común, tengan o no algún descendiente incapacitado, concediéndose por el testador a su cónyuge o pareja la posibilidad de realizar mejoras a favor de hijos o descendientes comunes, que pueden suponer la adjudicación de empresas familiares, debiendo siempre respetar las legítimas estrictas de los descendientes. En todo caso, el intento inicial del legislador de posponer el momento de la partición, no ha sido logrado en su totalidad, por cuanto si bien el testador puede señalar plazo para el ejercicio de la facultad de mejorar y distribuir, lo cierto es que, no habiéndose señalado plazo, el cónyuge sobreviviente tan sólo dispone de dos años para ejecutar la facultad conferida.

Básicamente, este precepto jurídico debe contemplarse desde la perspectiva de un patrimonio familiar y con él se pretende que el cónyuge del testador pueda mejorar a hijos o descendientes comunes mediante adjudicaciones de bienes concretos, por lo que bien puede tratarse de una empresa familiar, pudiendo así corregirse las ulteriores diferencias de fortuna o de otras circunstancias entre los hijos o descendientes, con la medida humanitaria y equitativa que supone la mejora a los que resulten más necesitados y mantener sin dividir dentro de la familia una explotación familiar.

Estamos pues hablando de la existencia de una especie de pacto sucesorio entre los cónyuges o de una delegación de la facultad de disponer mortis causa, concediéndose por el testador a su cónyuge la facultad de distribuir la herencia de forma semejante a la que tendría el propio causante.

En conclusión, el precepto que comentamos puede ser contemplado como una excepción a diversos mandatos del Código Civil: al art. 670, que deniega la posibilidad de dejar la formación de un testamento en todo o en parte al arbitrio de un tercero o de hacerlo por medio de comisario o mandatario; la de dejar al arbitrio de un tercero la subsistencia del nombramiento de herederos o legatarios y la de determinar las porciones en que hayan de suceder los instituidos nominalmente; al art. 830 que prohíbe encomendar a otro la facultad de mejorar; al art. 1057 que sólo permite al testador encomendar, por acto inter vivos o mortis causa, la simple facultad de hacer la partición a cualquier persona que no sea uno de los coherederos; y a los arts. 658 y 1271 que prohíben celebrar contratos sobre la herencia futura.

En conclusión nosotros consideramos que, dentro de la finalidades del precepto que comentamos, pueden perfectamente incluirse objetivos propios de una fiducia sucesoria, como son los de servir a la preservación de la integridad del patrimonio familiar, evitando su dispersión con el nombramiento de uno o de varios hijos o descendientes, tratar de favorecer su mejor elección posibilitando el aplazamiento de la designación al momento más adecuado, tratando de evitar así designaciones prematuras e inconvenientes que puedan darse con la división y para que no quiebre la unidad de la explotación familiar. 


\subsection{Los pactos sucesorios}

Para el Magistrado Zubiri de Salinas (2008), citando al Profesor Lacruz Verdejo, los pactos sucesorios son la ordenación mortis causa en la que la voluntad del instituyente queda vinculada a otra, del instituido o de un tercero, de forma que la disposición no puede revocarse por acto unilateral del causante.

Son pues las notas más importantes que caracterizan la naturaleza jurídica de los pactos sucesorios las siguientes: en primer lugar se trata de actos bilaterales y no como el testamento, que es acto individual del testador. $\mathrm{Y}$, en segundo lugar, son actos irrevocables frente a la libre revocabilidad del testamento, por supuesto con independencia de que concurra la mutua voluntad de las partes que celebraron el contrato sucesorio.

En nuestro Ordenamiento Jurídico, como norma general, se prohíbe la sucesión contractual tal como dice el art. 1271 del Cc, según el cual, "sobre la herencia futura no se podrá, sin embargo, celebrar otros contratos que aquellos cuyo objeto sea practicar entre vivos la división de un caudal y otras disposiciones particionales, conforme a lo dispuesto en el art. 1056". Por otro lado, son varios los preceptos del Cc de los que se deriva tal prohibición. Así, el art. 568, donde se dice que la sucesión se difiere por la voluntad del hombre manifestada en testamento o por disposición de la ley, lo que evidencia la exclusión de la sucesión contractual. En la misma línea, el art. 816, que proclama la nulidad de toda renuncia o transacción sobre la legítima futura. Y la misma orientación sigue el art. 991, que establece que no se podrá aceptar ni repudiar la herencia sin estar cierto de la muerte del causante a quien se haya de heredar y de su derecho a la herencia.

No obstante, son varios los ejemplos contractuales permitidos en nuestra legislación que tienen verdaderos efectos mortis causa, como la donación de bienes futuros para caso de muerte realizada entre los cónyuges en capitulaciones matrimoniales; contratos de compraventa que suelen celebrarse como anticipatorios de efectos sucesorios; contratos de renta vitalicia o de alimentos vitalicios o el contrato de seguro de vida para caso de muerte.

Los pactos sucesorios traen causa de las legislación es germánicas, como medio para resolver y ordenar los conflictos intersubjetivos que pudieran surgir en la sucesión de las personas. En cambio, su rechazo fue total para el Derecho Romano, sin duda como medio de intentar proteger al causante frente a sucesores no leales. Así, mientras que el Código Civil español, francés o italiano prohíben los contratos sucesorios, el Código Civil suizo o austriaco los permiten. Curiosamente en España existen diversas legislaciones autonómicas que sí permiten la existencia de pactos sucesorios, como Aragón, Cataluña, Islas Baleares y Navarra.

Como ya antes hemos indicado, en el derecho común español se podrá pactar sobre una empresa familiar que constituya una herencia futura, pero siempre y cuando se estipule dentro de lo permitido en el Código Civil, muy especialmente en lo relativo al respeto de la legítima de los herederos forzosos, pudiendo realizarse entre vivos la división y la 
partición de la explotación familiar sin variar ni la identidad de los llamados, ni el concepto por el que lo fueron, ni tampoco las atribuciones realizadas por el testador.

\section{Conclusiones}

Conforme a lo que hemos indicado, resulta evidente y se ha de resaltar la gran importancia que para el futuro de la empresa familiar tiene tanto la utilización de medios útiles para su gestión, como para la planificación de la sucesión.

En nuestro Ordenamiento Jurídico existen numerosas limitaciones legales que hacen muy difícil pactar la sucesión de una explotación familiar, por lo que sería conveniente que el legislador estuviese abierto para la realización de modificaciones legislativas que permitiesen la sucesión de la empresa al miembro de la familia mejor preparado, autorizando pactos sobre la herencia futura y que los cónyuges titulares de la empresa familiar pudiesen otorgar testamento de forma conjunta.

Por supuesto, no nos estamos refiriendo a que se establezca en la norma una libertad total de las personas para decidir sobre la sucesión de sus bienes por cuanto, consideramos, que el establecimiento de un régimen de legítimas a favor de los herederos forzosos del causante, es una forma más de protección de la familia que se ajusta al contenido de los arts. 33 y 39 de la CE, donde se reconoce el derecho a la herencia y la protección social, económica y jurídica de la familia. Lo que queremos poner de relieve es lo conveniente que sería para una empresa familiar el hecho de que su titular pudiese tener libertad para realizar pactos sucesorios que permitiesen y favoreciesen la continuidad de la misma, sin perjuicio de los derechos legítimos que pudieran corresponder a los herederos forzosos.

Creemos no faltar a la verdad si indicamos que la mayor parte de los titulares o fundadores de una empresa familiar pretenden, por un lado, conservar su explotación y, por otro, no perjudicar a sus hijos o descendientes. No obstante, no hay que olvidar que la experiencia es reveladora de que si no diseñan adecuadamente la sucesión de la empresa, a su fallecimiento, estará abocada a la desaparición, siendo una de las causas más importantes de la desaparición de empresas, sobre todo de pequeñas y medianas, la necesidad legal de tener que transmitir la explotación a los hijos en aplicación de los derechos legitimarios. Por esta razón, el legislador debería establecer mecanismos para flexibilizar el sistema de legítimas y, de esa forma, permitir la designación de un sucesor que quiera y que esté mejor preparado para la continuación de la misma, tratando de buscar una justa compensación entre el interés de mantener la supervivencia de la empresa y los derechos de los legitimarios, sobre todo en aquellas explotaciones familiares que, por su escasa capacidad económica, no pueden subsistir si tienen que ser explotadas por varias personas. Efectivamente, si en el caudal hereditario existen bienes suficientes para pagar la legítima a los herederos forzosos no habrá problemas, pero sí cuando es el adjudicatario quien debe correr con sus bienes privativos con la satisfacción de la misma. 
En conclusión, nuestra legislación es perjudicial para el desarrollo y la continuación de la empresa familiar por el juego del sistema de legítimas, por lo que se debería conceder al fundador de la explotación una mayor libertad para disponer de la misma en su herencia y para designar como sucesor a la persona o personas más y mejor preparadas, con la posibilidad de que se eligiese a una persona miembro de la familia, ya sea matrimonial o extramatrimonial o ya esté integrada por hombres y mujeres o por solo hombres o solo mujeres o, incluso, designando a un tercero ajeno al ámbito familiar.

La actual reforma del art. 1056 del Cc permitiendo el pago de la legítima en metálico al sucesor a quien el testador haya atribuido la explotación de la empresa familiar, con dinero extrahereditario y en un plazo de cinco años ha supuesto, en este sentido, un claro avance. No obstante, resulta insuficiente para el mantenimiento y la conservación de muchas empresas familiares, concretamente para que el fundador planifique la sucesión de su explotación o para vencer resistencias de familiares a abandonar sus puestos en un momento determinado que convenga a la empresa; para poder incorporar nuevos gestores no familiares a la dirección de la explotación; para solventar posibles conflictos financieros derivados del cambio generacional o, en definitiva, para garantizar que el sucesor de la empresa sea el mejor y el más competente gestor o administrador, aunque no forme parte de su ámbito familiar.

\section{Bibliografía}

Bernaldo de Quirós, M. (1991). Comentarios del Código Civil, pp. 645 y ss.

Gallo, M.A. (1998). "La sucesión de la empresa familiar", Colección de Estudios de Informes de la Caixa, p.7.

García Urbano, J.Mª (1991). Comentarios del Código Civil, p. 797.

Informe de la Comisión Especial del Senado para el Estudio Jurídico de la Empresa Familiar (2001), BOCE, Senado, 23 de noviembre de 2001.

Parra Lucán, MaA. (2008). "Legítimas, libertad de testar y transmisión de un patrimonio", Manuales de Formación Continuada del CGPJ pp. 487 y ss. y 566.

Reyes López, Mả. (2005). El patrimonio familiar, profesional y empresarial y sus protocolos, pp. 110 a 115.

Vázquez Iruzubieta, C. (1997). Doctrina y Jurisprudencia del Código Civil, páginas 2120 y ss.

Zubiri de Salinas, F. (2008). "Instrumentos de Ordenación de la Sucesión de Ordenación de la Sucesión por Causa de Muerte", Manuales de Formación Continuada del CGPJ, p. 197. 